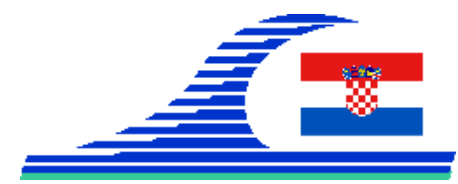

\title{
Impact of urbanized rivers inputs on sediments of two contrasted coastal Mediterranean areas: Toulon Bay (France) and St-Georges Bay (Lebanon)
}

\author{
Amonda EL HOUSSAINY ${ }^{1,2}$, Carine ABI-GHANEM ${ }^{3}$, Gaël DURRIEU ${ }^{1}$, \\ Duc Huy DANG ${ }^{1,4}$, Céline MAHFOUZ ${ }^{2}$, Dario OMANOVIĆ ${ }^{5}$, \\ Sebastien D'ONOFRIO ${ }^{1}$, Jean-Ulrich MULLOT ${ }^{6}$, Gaby KHALAF ${ }^{2}$, \\ Cédric GARNIER ${ }^{1}$
}

1. PROTEE, Université de Toulon, CS 60584, 83041 Toulon Cedex 9, France. amonda.houssainy@gmail.com,cgarnier@univ-tln.fr,gael.durrieu@univ-tln.fr, sebastien.d-onofrio@univ-tln.fr

2. CNRS, National Centre for Marine Sciences, P.O.Box 534, Batroun, Lebanon. bihar@cnrs.edu.lb,celine.mahfouz@gmail.com

3. Lebanese University, Faculty of Sciences III, Tripoli, Lebanon. carine.a.ghanem@hotmail.fr

4. Trent School of the Environment, Trent University, 1600 West Bank Drive, Peterborough, ON Canada, K9L 0G2. huydang@trentu.ca

5. Ruđer Bošković Institute, Division for marine and environmental research, Bijenička cesta 54, 10000 Zagreb, Croatia. omanovic@irb.hr

6. LASEM, Base Navale Toulon, BP 61, 83800 Toulon Cedex 9, France. jean-ulrich.mullot@intradef.gouv.fr

\begin{abstract}
:
Mediterranean Sea (MS) is a semi-enclosed sea hosting a high population density and is exposed to numerous anthropogenic activities that contaminate the surrounding environment with pollutants such as trace metals (TM). TM distribution is influenced by numerous (bio) geochemical processes which can turn sediments into a secondary source of contaminants for the ecosystem. In this study, we investigate TM contamination in two coastal Mediterranean sites: Toulon Bay (Northwestern MS, France) and St-Georges Bay (Eastern MS, Lebanon). Both sites are submitted to anthropogenic pressures and host urbanized coastal rivers (Las River and Beirut River, respectively). Even, if Las River contribution is non-negligible for few elements but it contributes in dilution of past pollutions of the bay. In contrast, sediments from St-Georges Bay are impacted by several anthropogenic activities transported through Beirut River. Additionally, early diagenesis highly affects TM mobility in the sediments of these two ecosystems.
\end{abstract}


Mediterranean rocky coasts:

Features, processes, evolution and problems

Keywords: Mediterranean Sea, Coastal, Rivers, Trace metals, Sediments, Early diagenesis, Mobility.

\section{Introduction}

Mediterranean coastal areas are exposed to numerous anthropogenic pressures, e.g. tourism, maritime traffic, marinas, aquaculture, sewage outfall and industrial activities; carrying pollutants such as trace metals (TM) which would be settled in sediments as final sinks. Moreover, (bio) geochemical processes such as early diagenesis influence TM sedimentary mobility, which can constitute a potential risk for the surrounding environments. In this context, we investigate the impact of two urbanized river inputs on coastal Mediterranean sediments.

Toulon Bay is a semi-enclosed bay located in the NW Mediterranean Sea, SE of French coast where the small urbanized river "Las" with terrestrial/anthropogenic inputs flows into the bay. Coastal sediments present strong multi-contamination due to past/present activities $\left(2^{\text {nd }}\right.$ World War, $1^{\text {st }}$ French Navy harbor, aquaculture, marinas) (TESSIER et al., 2011). St-Georges Bay is in the Eastern Mediterranean Sea of Beirut-Lebanon. This bay is characterized by the presence of a seasonal highly contaminated river "Beirut", industrial effluents, urban sewage and a nearby dumpsite that strongly contaminate sediments of this bay (ABI-GHANEM, 2008).

\section{Sampling and analyses}

Sediment core sampling was performed in 2016 at both sites and collected in front of Las and Beirut Rivers by divers. Each core was sliced with 2-cm resolution within 2-h of sampling under inert atmosphere $\left(\mathrm{N}_{2}\right)$ to preserve redox conditions. After centrifugation, pore waters were retrieved and filtered $(0.2 \mu \mathrm{m}$, cellulose nitrate, Sartorius). Freeze-dried solid fraction was sieved $(2 \mathrm{~mm})$ and crushed. Particulate organic/inorganic carbon and total nitrogen were analyzed in sediments. Dissolved organic/inorganic carbon and diagenetic tracers were analyzed in extracted pore waters and overlaying seawater. Dissolved and total contents of minor/trace elements were analyzed by HR - ICP/MS.

\section{Results and discussion}

The Las River deposit shows a lower content of terrigenous elements than St-Georges bay sediments, such as $\mathrm{Al}$ (see Figure $1 \mathrm{~A}$ ), Li, Be and $\mathrm{Mn}$ (data not shown). The increase in concentration of these lithogenic elements in LAS3 compared to LAS1 and 2, indicates a continuous settlement of coarse to fine particles along Las deposit area.

Along the Las River transect (LAS1 to LAS3), concentrations of trace elements $(\mathrm{Pb}$, $\mathrm{Cu}$ ) increase suggesting a dilution effect of Las River particles. However, the Cd profiles at LAS1 would indicate that Las River significantly contributes in Cd inputs in Toulon Bay. In addition, higher concentration of these trace metals in deep sediments could probably be related to an historic and anthropogenic inputs or to an authigenic 
Mediterranean rocky coasts:

formation (see Figure 1A and 1B). On the other hand, $\mathrm{Pb}, \mathrm{Cd}$ and $\mathrm{Cu}$ profiles in StGeorges bay are characterized by a superficial enrichment and then a constant and slight decrease of these trace metals levels with depth (see figure 1).

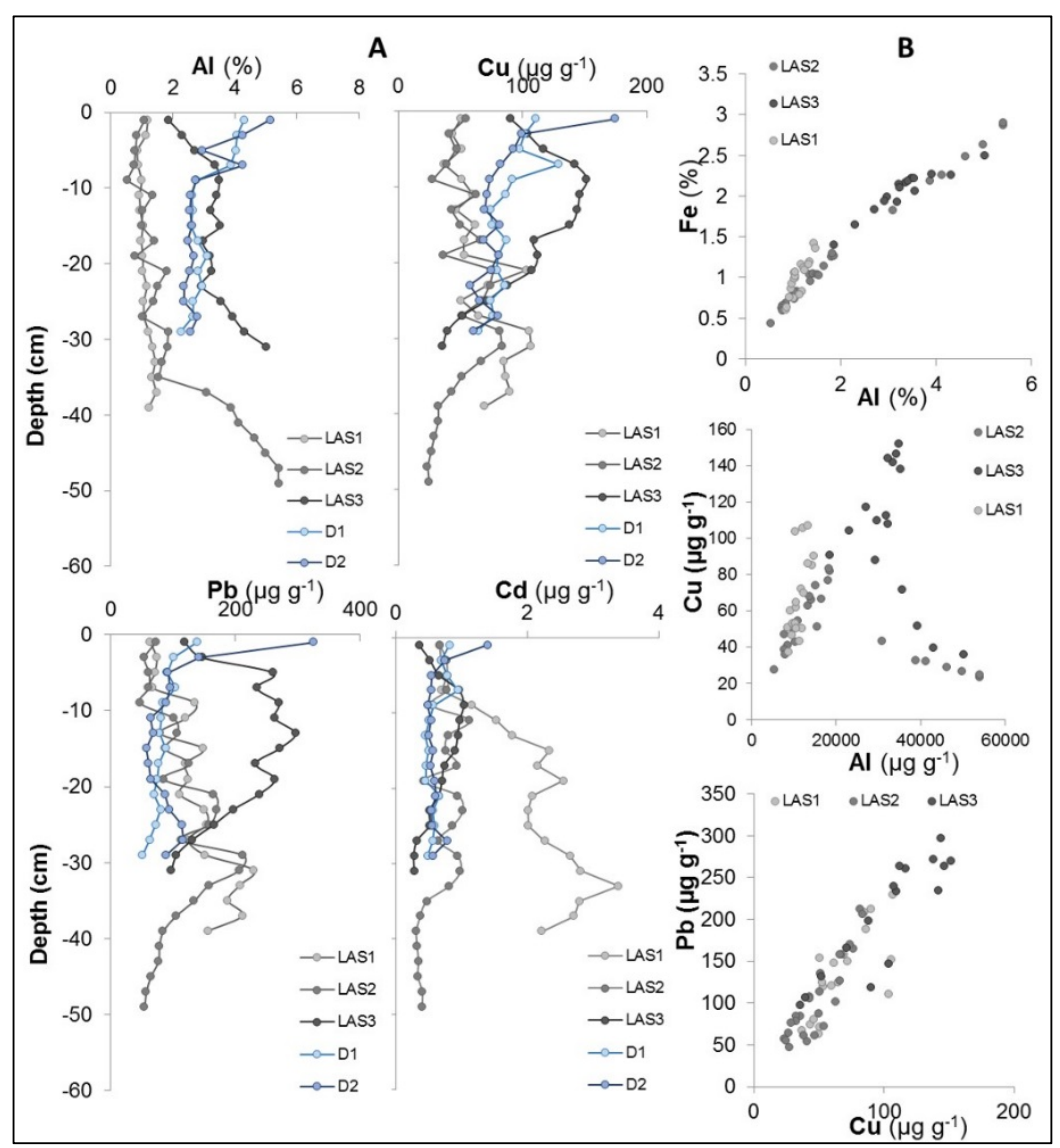

Figure 1. (A) Depth profiles of $\mathrm{Al}, \mathrm{Pb}, \mathrm{Cd}$ and $\mathrm{Cu}$ contents in sediments cores from Toulon Bay and St-Georges Bay.

(B) Correlation between $\mathrm{Fe}$ and $\mathrm{Al}, \mathrm{Cu}$ and $\mathrm{Al}, \mathrm{Cu}$ and $\mathrm{Pb}$ in Toulon Bay sediments.

Usual diagenetic sequence is clearly visible for Fe, Mn (see Figure 2) and ammonium/phosphates/inorganic carbon/sulphate/sulphide (data not shown) in pore water depth profiles at Toulon and St-Georges bays. Early diagenesis markedly influences on the remobilization of trace elements such as $\mathrm{Cu}$ and $\mathrm{Pb}$. It is noticeably shown in Toulon Bay, especially at LAS2 where a strong increase at $\sim 30 \mathrm{~cm}$ is visible, reaching levels much higher than previously noticed at other locations of the Bay outside the influence of direct terrigenous inputs.

However, in St-Georges Bay, dissolved $\mathrm{Cu}$ and $\mathrm{Pb}$ profiles present superficial peaks located at the same levels as Fe and/or Mn dissolved peaks, suggesting a remobilization of these trace elements during $\mathrm{Mn}$ and $\mathrm{Fe}$ oxides and oxyhydroxide reduction (see figure 2). 
Mediterranean rocky coasts:

Features, processes, evolution and problems

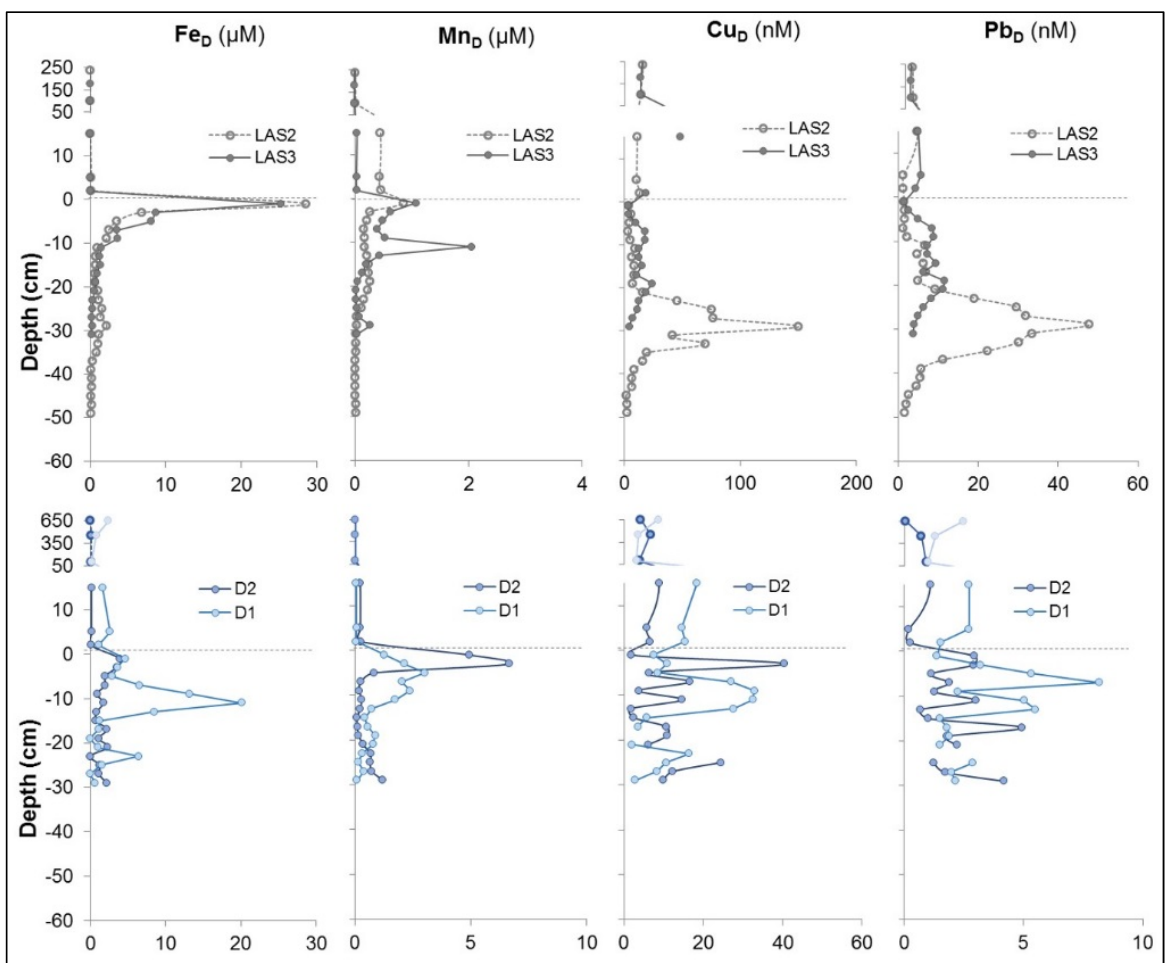

Figure 2. Concentration depths profiles of $\mathrm{Fe}, \mathrm{Mn}, \mathrm{Cu}$ and $\mathrm{Pb}$ in pore water from Toulon Bay (upper panel) and St-Georges Bay (lower panel).

\section{Conclusion}

Although Las River contributes to the contamination of Toulon Bay by Cd, the actual discharge of particles into the bay tend to "naturally" dilute past pollutions of the bay (due to $2^{\text {nd }} \mathrm{WW}$ ), potentially improving its status with time. Contrarily, obtained results in St-Georges Bay suggest a superficial coastal contamination for the studied trace elements, probably related to Beirut rivers inputs.

However, early diagenetic processes clearly mobilize trace elements, making such sediments a potential source of contaminants for the overlaying seawater column.

\section{References}

TESSIER E., GARNIER C., MULLOT J.-U., LENOBLE V., ARNAUD M., RAYNAUD M., MOUNIER S. (2011). Study of the spatial and historical distribution of sediment inorganic contamination in the Toulon bay (France). Marine Pollution Bulletin, Vol. 62 (10), 2075-2086. doi.org/10.1016/j.marpolbul.2011.07.022

ABI-GHANEM C. (2008). Spéciation des trois éléments trace mercure, plomb et cadmium dans les sédiments des zones côtières libanaises. Thèse de l'Institut des Sciences et Industries du Vivant et de l'Environnement, Agro Paris Tech, Paris. https://hal.archives-ouvertes.fr/pastel-00005015 